\title{
Ogunlesi TA $\quad$ CC-BY A survey of Paediatricians on evidence-based medical practice in Nigeria
}

DOI:http://dx.doi.org/10.4314/njp.v45i3.5

Accepted: 17th September 2018

Ogunlesi TA ( $\mathbf{~})$

Department of Paediatrics,

Olabisi Onabanjo University

Teaching Hospital,

P. O. Box 652, Sagamu-121001NG,

Ogun State, Nigeria

Email:

tinuade_ogunlesi@yahoo.co.uk

\begin{abstract}
Background: The increasing need for a uniform standard of medical practice necessitates an examination of the impediments to the use of evidencebased medicine.

Objective: To examine the knowledge, perceived barriers to the use of evidence-based medicine and the associated profession-related factors among paediatricians in Nigeria.

Methods: A cross-sectional survey of paediatricians in Nigeria was conducted between March and April 2013 by Email. The knowledge about evidence-based medicine and systematic reviews was tested using a structured questionnaire and the responses were provided on three-item Likert scale.

Results: The response rate in the survey was $56.5 \%$ (65/115). Almost $37 \%$ of the participants had postgraduate qualification in or before year 1999 (Group I). Majority $(93.8 \%)$ of the respondents believed that EBM should form the basis for decision making in
\end{abstract}

clinical practice while $53.9 \%$ believed that EBM is more suitable for the developed world. The overall mean knowledge score was $77.6 \%$. Knowledge about EBM was rated high among $80 \%$ of the participants and the proportion with high knowledge was not significantly associated with EBM use in routine practice or prior EBM training. Some of the perceived barriers to EBM use included lack of skills for understanding statistics $(81.6 \%)$, lack of incentives for the use of EBM $(64.7 \%)$, lack of time $(44.6 \%)$ and lack of conclusive evidences (44.6\%).

Conclusion: The knowledge of EBM among Nigerian paediatricians was good but a high proportion regarded lack of skills to perform statistical analysis required for EBM as a major barrier to the practice of EBM.

Key words: Evidence-based medicine, Systematic review, Research, Paediatricians.

\section{Introduction}

The prime role of research in driving clinical practice has not changed over the years but the application of research in guiding clinical practice is globally getting focused on the critical need for evidences guiding every aspect of decision taking in medical practice. ${ }^{1}$ The contents of textbooks, clinical observations and opinions passed down from senior colleagues have hitherto, formed the bedrock of guidance for making clinical decisions. $^{2}$ With the increasing use of evidence-based medicine, clinical decisions are gradually shifting towards the provisions of management protocols and treatment guidelines rather than textbook recommendations and opinions formed in the course of training and practice. In brief, evidence-based medicine strictly entails adherence to the current best practices for the utmost benefit of the patient. This is necessitated by the need for a more guided approach rather than the haphazard access to a large volume of pockets of research outputs from various parts of the world, some with conflicting reports and some with inadequate information to guide practice. ${ }^{2,3}$ Therefore, evidence-based medicine appears to be the most efficient way of delivering clinical care in the context of rapidly changing trends in medical practice.

At the tertiary level of care, the tripod of clinical duties includes service, teaching and research. A previous study conducted among medical specialists in Nigeria ${ }^{4}$ showed that research function was ranked third by $64.7 \%$ of the participants in that study, behind service and training. A similar study revealed that the spectrum of research tilted more towards low-budget crosssectional surveys and retrospective studies due to the challenges of lack of funds, work overload, time constraints and insufficient infrastructural supports. ${ }^{5}$ In the same study, $37.5 \%$ of specialists had never been in- 
volved in clinical trials. Incidentally, randomized clinical trials, which represent the peak of clinical evidence through the benefits of elimination of bias, form the core of evidence-based medicine. ${ }^{1}$

Evidence-based medicine entails the identification of an intervention or relationship of interest, gathering relevant high-quality randomized controlled trials and conducting statistical analysis, using meta-analysis, to assess the quality of evidence in support of specific outcome variables of interest. ${ }^{1,6}$ This is the basis of the use of various treatment guidelines and management protocols for clinical decision in various parts of the developed world. Commonly accessed resources for evidence -based medicine include the Cochrane Library and the World Health Organisation Reproductive Health Library. These are the commonly used databases which provide information on virtually all aspects of medicine. Of utmost relevance to the practice of paediatrics are the Neonatal and the Infectious Diseases Review Groups which presently contains hundreds of systematic reviews.

With the drive to develop treatment protocols for common paediatric disorders in Nigeria, it is essential to examine the acceptability and understanding of the concept of evidence-based medicine among paediatricians. Therefore, the objective of this study was to examine the knowledge, perceived barriers to the use of evidencebased medicine and the associated profession-related factors among paediatricians in Nigeria.

\section{Materials and Methods}

This was a cross-sectional questionnaire-based survey of paediatricians who practiced in Nigeria. The study was carried out electronically using email-distribution of questionnaire to paediatricians on a mailing list. The research was conducted in agreement with the Helsinki Declaration for Human subjects research. The inclusion criteria included Postgraduate Fellowship in Paediatrics obtained from either the West African College of Physicians or the National Postgraduate Medical College of Nigeria and employment as a Consultant Paediatrician within Nigeria. The study was carried out between March and April 2013.

The minimum sample size was determined using the formula; $\mathrm{n}=\left(\mathrm{z}^{2} \times \mathrm{p} \times \mathrm{q}\right) / \mathrm{d}^{2}$ where $\mathrm{z}=1.96, \mathrm{p}=0.05$ (proportion of respondents in a similar study who used EBM to take clinical decisions ${ }^{7}$ ), $q=0.95$ and $d=0.05$. The calculated minimum sample size was 72 but additional 50\% (36) was added to increase the strength of the study. Therefore, the final sample size was 104 .

Out of the 426 names on the mailing list of paediatricians, 78 duplicated names, names with incomplete data (such as place of practice and year of postgraduate qualification) and names of deceased paediatricians were removed, leaving 348 names. Thereafter, the 348 names were arranged alphabetically and systematic random sampling was done using a sampling interval of three resulting in 115 rather than the targeted 104. The selected 115 paediatricians were enrolled into survey and were contacted via email. The email contained a statement of introduction of the study as well as the request for consent. The email message specified that response to the survey meant consent for enrolment into the study and anyone not willing to participate in the study was allowed to disregard the request. The data collection was carried out between $3^{\text {rd }}$ March and $5^{\text {th }}$ April 2013.

The research tool was a self-designed close ended questionnaire with three sections using information gathered from the Cochrane Handbook for Systematic Reviews of Interventions as a template in most cases. ${ }^{8}$ The first section obtained data on professional parameters such as the year of postgraduate qualification, location of practice in terms of geopolitical zone, sector of practice (public or private), setting of practice (academic or nonacademic), current use of EBM in clinical practice and history of previous formal training in EBM. The second section tested the knowledge of participants about EBM using general statements covering a wide scope of the principles and tenets of EBM as well as test of understanding and ability to teach specific statistical items. The third section assessed the participants' attitude to perceived barriers to the use of EBM in clinical practice. Some of the statements were framed in the positive context and others were framed in the negative context and the responses were obtained using a three-item Likert Scale - Agreed, Undecided and Disagreed. The responses to each statement were uniformly assessed without weighting; they were scored 3, 2 and 1 depending on the context of positivity or negativity; the option of "agreed" for a negatively-framed statement earned a score of " 1 " just as a response of "disagreed" for a negatively-framed statement earned a score of " 3 " and vice versa. For each participant, the total score was converted to percentage based on the number of statements responded to. Knowledge scores of $75 \%$ and above were classified as "high" while scores less than $75 \%$ were classified as "low" scores. The mean percentage knowledge score was determined for each group of participants.

\section{Data management}

Only completed questionnaires returned by email were pooled for analysis using a spreadsheet created with the Microsoft Excel software. Descriptive and inferential statistics were conducted using the SPSS version 20.0 software. Hypotheses were tested using the Chi Square test with either Yate's correction or the Fisher's Exact test as necessary, for proportions of categorical variables and the Student's t-test for the means $( \pm$ Standard deviations) of continuous variables. Professional characteristics of the respondents (year of postgraduate qualification, sector of practice, setting of practice, use of EBM in clinical practice and training in EBM) were related to the knowledge score as well as the perceived barriers to EBM. $P$ values less than 0.05 were accepted as statistical significance. 


\section{Results}

General description of the respondents

Sixty-five out of the 115 participants returned completely filled questionnaire giving a response rate of $56.5 \%$. The 65 paediatricians were distributed across the geo-political zones of the country as follows: 24 $(36.9 \%)$ from the south-west, $16(24.6 \%)$ from the south -east, $10(15.5 \%)$ from the south-south, $6(9.2 \%)$ each from the north-west and north-central and 3 (4.6\%) from the north-east.

The distribution of the respondents according to the year of post-graduate qualification was as follows: $4(6.1 \%)$, $20(30.8 \%), 30(46.2 \%)$ and $11(16.9 \%)$ for $1980-1989$, 1990-1999, 2000-2009 and $\geq 2010$ respectively. They were re-grouped into two as $1980-1999$ (Group I) and 2000 and above (Group II) translating to $24(36.9 \%)$ in Group I and $41(63.1 \%)$ in Group II. The major subspecialties included neonatology $(17 ; 26.2 \%)$, cardiology $(9,13.9 \%)$, haematology and nephrology $(7 ; 10.8 \%$ each), endocrinology, infectious diseases and ambulatory paediatrics $(6 ; 9.2 \%$ each). The remaining 7 $(10.7 \%)$ included neurodevelopmental paediatrics, gastroenterology and nutrition and respiratology.

Most of the respondents $(53 ; 81.5 \%)$ practiced in the public sector; $33(50.8 \%)$ and $29(44.6 \%)$ practiced in Teaching Hospital and specialist hospitals (including Federal Medical Centres) respectively. The settings of practice were sub-classified into two: academic (33; $50.8 \%)$ and non-academic $(32 ; 49.2 \%)$. Fifty-two $(80.0 \%)$ were involved in undergraduate training while all the respondents had experience with postgraduate training. Fifty-nine $(90.8 \%)$ respondents used evidencebased medicine in their routine clinical practice but only $24(36.9 \%)$ actually had training in evidence-based medicine. While all the respondents in Group I $(n=24)$ used EBM in clinical practice, $35(85.4 \%)$ of Group II used EBM in clinical practice (Fisher's Exact Test = $5.872 ; \mathrm{p}=0.07)$. A significantly larger proportion of respondents in Group I $(17 ; 70.8 \%)$ received training on EBM compared to respondents sin Group II $(7 ; 17.1 \%)$ $\left(\chi^{2}=18.786 ; p<0.001\right)$.

\section{General knowledge and attitude of respondents about EBM}

As shown in Table 1, all the respondents agreed that current research findings are useful in routine care of patients, $76.9 \%$ craved for further use of EBM in their daily practices while $92.3 \%$ were willing to learn the skills required to incorporate EBM into their routine practices. However, $86.1 \%$ believed EBM is patientcentred, improves the quality of care available to patients $(89.3 \%)$, should form the basis of decision making in clinical practice $(93.8 \%)$ and should improve the design of medical curriculum $(83.1 \%)$. On the other hand, the respondents identified drawbacks such as EBM not taking into consideration the limitations in clinical practice $(55.4 \%)$ and EBM being more suitable for practice in the developed world compared to the developing world $(53.9 \%)$.

\begin{tabular}{|c|c|c|c|c|}
\hline Suggestions about EBM & Agreed & $\begin{array}{l}\text { Unde- } \\
\text { cided }\end{array}$ & $\begin{array}{c}\text { Dis- } \\
\text { agreed }\end{array}$ & Total \\
\hline $\begin{array}{l}\text { Current research findings } \\
\text { are useful in the day-to-day } \\
\text { management of my patients }\end{array}$ & $\begin{array}{c}65 \\
(100.0)\end{array}$ & $0(0.0)$ & $0(0.0)$ & 65 \\
\hline $\begin{array}{l}\text { Adoption of evidence-based } \\
\text { practice places too many } \\
\text { demands on my workload }\end{array}$ & $\begin{array}{c}23 \\
(35.4)\end{array}$ & $4(6.2)$ & $\begin{array}{c}38 \\
(56.4)\end{array}$ & 65 \\
\hline EBM is patient centered & $\begin{array}{c}56 \\
(86.1)\end{array}$ & $4(6.2)$ & $5(7.7)$ & 65 \\
\hline $\begin{array}{l}\text { EBM is of limited value in } \\
\text { paediatric practice }\end{array}$ & $3(4.6)$ & $4(6.2)$ & $\begin{array}{c}58 \\
(89.3)\end{array}$ & 65 \\
\hline $\begin{array}{l}\text { Literature and research } \\
\text { findings are useful in paedi- } \\
\text { atric practice }\end{array}$ & $\begin{array}{c}62 \\
(95.4)\end{array}$ & $3(4.6)$ & $0(0.0)$ & 65 \\
\hline $\begin{array}{l}\text { I need to increase the use of } \\
\text { evidence in my daily prac- } \\
\text { tice }\end{array}$ & $\begin{array}{c}50 \\
(76.9)\end{array}$ & $15(23.1)$ & $0(0.0)$ & 65 \\
\hline $\begin{array}{l}\text { I am interested in learning } \\
\text { skills to incorporate EBM in } \\
\text { my practice }\end{array}$ & $\begin{array}{c}60 \\
(92.3)\end{array}$ & $5(7.7)$ & $0(0.0)$ & 65 \\
\hline $\begin{array}{l}\text { EBM improves the quality } \\
\text { of patient care }\end{array}$ & $\begin{array}{c}58 \\
(89.3)\end{array}$ & $6(9.2)$ & $1(1.5)$ & 65 \\
\hline $\begin{array}{l}\text { EBM does not take into } \\
\text { consideration the limitations } \\
\text { in clinical practice }\end{array}$ & $\begin{array}{c}36 \\
(55.4)\end{array}$ & $7(10.8)$ & $\begin{array}{c}22 \\
(33.8)\end{array}$ & 65 \\
\hline $\begin{array}{l}\text { Reimbursement rate will } \\
\text { increase with incorporation } \\
\text { of EBM into paediatric } \\
\text { practice }\end{array}$ & $\begin{array}{c}12 \\
(18.5)\end{array}$ & $40(61.4)$ & $\begin{array}{c}13 \\
(19.9)\end{array}$ & 65 \\
\hline $\begin{array}{l}\text { Strong evidence is lacking } \\
\text { in most interventions used }\end{array}$ & $\begin{array}{c}23 \\
(35.5)\end{array}$ & $15(23.0)$ & $\begin{array}{c}27 \\
(41.5)\end{array}$ & 65 \\
\hline $\begin{array}{l}\text { EBM should form the basis } \\
\text { of decision-making in clini- } \\
\text { cal practice }\end{array}$ & $\begin{array}{c}61 \\
(93.8)\end{array}$ & $2(3.1)$ & $2(3.1)$ & 65 \\
\hline $\begin{array}{l}\text { EBM does not take into } \\
\text { consideration, patients' } \\
\text { preferences }\end{array}$ & $\begin{array}{c}25 \\
(38.5)\end{array}$ & $7(10.8)$ & $\begin{array}{c}33 \\
(50.7)\end{array}$ & 65 \\
\hline $\begin{array}{l}\text { EBM is useful in designing } \\
\text { the medical curriculum }\end{array}$ & $\begin{array}{c}54 \\
(83.1)\end{array}$ & $11(16.9)$ & $0(0.0)$ & 65 \\
\hline $\begin{array}{l}\text { EBM is most useful for } \\
\text { paediatric practice in the } \\
\text { developed world }\end{array}$ & $\begin{array}{c}35 \\
(53.9)\end{array}$ & $11(16.9)$ & $\begin{array}{c}19 \\
(29.2)\end{array}$ & 65 \\
\hline
\end{tabular}

EBM - Evidence-based Medicine

In the assessment of the skills required to use EBM, Table 2 shows that some of the respondents did not understand but will like to learn heterogeneity (44.6\%) while $46.1 \%, 52.3 \%, 50.8 \%, 46.1 \%, 50.8 \%$ and $64.6 \%$ understood meta-analysis, systematic review, assessment of publication bias, literature search strategies, study designs and clinical significance of study findings respectively. The highest proportion of the respondents demonstrated the willingness to teach literature search strategies $(41.5 \%)$ while only $13.8 \%$ understood and could teach the use of Cochrane Library Database.

In Table 3 lack of the skills for understanding statistics and lack of skills for locating best research evidence were the leading perceived barriers to the use of EBM as identified by $81.6 \%$ and $73.8 \%$ respectively of the respondents. The fear of medicolegal tussle arising from the use of EBM was identified by only $27.7 \%$ as a barrier to the use of EBM. The proportions of respondents who agreed or disagreed with lack of time and lack of conclusive evidence as barriers to the use of EBM were almost comparable (44.6\%). All the respondents agreed 
that EBM should be incorporated into Continuing Medical Education activities and into postgraduate medical curriculum while only $56(86.2 \%)$ agreed that EBM should be incorporated into medical undergraduate training curriculum whereas $9(13.8 \%)$ were neutral.

\begin{tabular}{|c|c|c|c|c|}
\hline & $\begin{array}{l}\text { It is not } \\
\text { important } \\
\text { I under- } \\
\text { stand }\end{array}$ & $\begin{array}{l}\text { I do not } \\
\text { under- } \\
\text { stand but } \\
\text { will like } \\
\text { to }\end{array}$ & $\begin{array}{l}\text { I have } \\
\text { some } \\
\text { under- } \\
\text { standing }\end{array}$ & $\begin{array}{l}\text { I under- } \\
\text { stand and } \\
\text { could } \\
\text { teach } \\
\text { others }\end{array}$ \\
\hline$\overline{\text { Relative Risk }}$ & $0(0.0)$ & $23(35.4)$ & $23(35.4)$ & $\overline{19(29.3)}$ \\
\hline Meta-analysis & $0(0.0)$ & $21(32.3)$ & $30(46.1)$ & 14 (21.5) \\
\hline $\begin{array}{l}\text { Systematic Re- } \\
\text { view }\end{array}$ & $0(0.0)$ & $15(23.1)$ & $34(52.3)$ & $16(24.6)$ \\
\hline Heterogeneity & $0(0.0)$ & $29(44.6)$ & $20(30.8)$ & $16(24.6)$ \\
\hline Publication bias & $0(0.0)$ & $20(30.8)$ & $33(50.8)$ & $12(18.5)$ \\
\hline $\begin{array}{l}\text { Literature Search } \\
\text { Strategies }\end{array}$ & $0(0.0)$ & $8(2.3)$ & $30(46.1)$ & $27(41.5)$ \\
\hline Study designs & $0(0.0)$ & $10(15.4)$ & $33(50.8)$ & $22(33.8)$ \\
\hline $\begin{array}{l}\text { Evaluating the } \\
\text { validity of a study }\end{array}$ & $0(0.0)$ & $21(32.3)$ & $26(40.0)$ & $18(27.7)$ \\
\hline $\begin{array}{l}\text { The clinical sig- } \\
\text { nificance of study } \\
\text { results }\end{array}$ & $0(0.0)$ & $7(10.8)$ & $42(64.6)$ & $16(24.6)$ \\
\hline $\begin{array}{l}\text { Using the Coch- } \\
\text { rane Library Data- } \\
\text { base }\end{array}$ & $0(0.0)$ & $25(38.5)$ & $31(47.7)$ & $9(13.8)$ \\
\hline
\end{tabular}

EBM - Evidence-based Medicine

\begin{tabular}{|c|c|c|c|}
\hline & Agreed & $\begin{array}{l}\text { Unde- } \\
\text { cided }\end{array}$ & $\begin{array}{l}\text { Dis- } \\
\text { agreed }\end{array}$ \\
\hline Lack of time & $29(44.6)$ & $6(9.2)$ & $30(46.2)$ \\
\hline Lack of conclusive evidence & $29(44.6)$ & $8(12.3)$ & $28(43.1)$ \\
\hline Lack of computing resources & $37(56.9)$ & $5(7.7)$ & $23(35.4)$ \\
\hline $\begin{array}{l}\text { Lack of access to electronic } \\
\text { databases }\end{array}$ & $37(57.0)$ & $8(12.2)$ & $20(30.8)$ \\
\hline $\begin{array}{l}\text { Lack of skills for locating } \\
\text { best research evidence }\end{array}$ & $48(73.8)$ & $5(7.7)$ & $12(18.5)$ \\
\hline $\begin{array}{l}\text { Lack of skills for under- } \\
\text { standing statistics }\end{array}$ & $53(81.6)$ & $0(0.0)$ & $12(18.4)$ \\
\hline $\begin{array}{l}\text { Lack of incentive for using } \\
\text { EBM }\end{array}$ & $22(64.7)$ & $8(12.3)$ & $15(23.0)$ \\
\hline $\begin{array}{l}\text { Fear of medico-legal tussles } \\
\text { arising from practice }\end{array}$ & $18(27.7)$ & $\begin{array}{l}11 \\
(16.9)\end{array}$ & $36(55.4)$ \\
\hline
\end{tabular}

EBM - Evidence-based Medicine

\section{Assessment of knowledge of the respondents}

The knowledge scores for the entire study population ranged between $64.0 \%$ and $88.0 \%$ with overall mean score of $77.6 \% \pm 5.6 \%$. The mean scores for the various groups of participants were comparable as shown in Table 4. The assessment of knowledge showed that 52 $(80.0 \%)$ and $13(20.0 \%)$ participants had high and low knowledge scores respectively. Table 5 shows that the proportions of respondents with high knowledge score were comparable across groups: duration of practice ( $p$ $=0.139)$, sector of practice $(\mathrm{p}=0.936)$ and setting of practice $(\mathrm{p}=0.710)$. In addition, EBM use in practice and prior EBM training were also not significantly associated with high knowledge scores $(\mathrm{p}=0.335$ and $\mathrm{p}=$ 0.947 respectively).

\begin{tabular}{lllll}
\hline $\begin{array}{l}\text { Table 4: Comparison of mean knowledge scores among com- } \\
\text { parison groups }\end{array}$ & Groups & $\begin{array}{l}\text { Mean } \\
\text { scores (\%) }\end{array}$ & t & $\begin{array}{l}\text { p- } \\
\text { values }\end{array}$ \\
\hline $\begin{array}{l}\text { Duration of } \\
\text { practice }\end{array}$ & Group I & $79.0 \pm 4.5$ & 1.583 & 0.118 \\
& Group II & $76.7 \pm 6.1$ & & \\
$\begin{array}{l}\text { Sector of prac- } \\
\text { tice }\end{array}$ & Public & $78.1 \pm 5.4$ & 1.347 & 0.183 \\
& Private & $75.6 \pm 0.4$ & & \\
$\begin{array}{l}\text { Setting of prac- } \\
\text { tice }\end{array}$ & Academic & $76.5 \pm 4.5$ & -1.604 & 0.114 \\
& Non- & $76.0 \pm 1.4$ & & \\
EBM Use in & Yes & $77.8 \pm 5.8$ & 0.734 & 0.466 \\
clinical practice & No & $76.0 \pm 1.4$ & & \\
& Yes & $78.6 \pm 4.4$ & 1.087 & 0.281 \\
EBM Training & No & $77.0 \pm 6.2$ & & \\
\hline
\end{tabular}

\begin{tabular}{|c|c|c|c|c|}
\hline $\begin{array}{l}\text { Character- } \\
\text { istics }\end{array}$ & & High Score & $\begin{array}{l}\text { Low } \\
\text { Score }\end{array}$ & Statistics \\
\hline \multirow[t]{2}{*}{$\begin{array}{l}\text { Duration } \\
\text { of practice }\end{array}$} & $\begin{array}{l}\text { Group I } \\
(\mathrm{n}=24)\end{array}$ & 22 (91.7) & $2(8.3)$ & \multirow[t]{2}{*}{$\begin{array}{l}\chi^{2}=2.184 \\
p=0.139^{*}\end{array}$} \\
\hline & $\begin{array}{l}\text { Group II } \\
(\mathrm{n}=41)\end{array}$ & 30 (73.2) & $11(26.8)$ & \\
\hline \multirow[t]{2}{*}{$\begin{array}{l}\text { Sector of } \\
\text { practice }\end{array}$} & $\begin{array}{l}\text { Private } \\
(\mathrm{n}=12)\end{array}$ & $9(75.0)$ & $3(25.0)$ & \multirow[t]{2}{*}{$\begin{array}{l}\chi 2=0.006 ; p \\
=0.936^{*}\end{array}$} \\
\hline & $\begin{array}{l}\text { Public } \\
(\mathrm{n}=53)\end{array}$ & $43(81.1)$ & $10(18.9)$ & \\
\hline \multirow[t]{2}{*}{$\begin{array}{l}\text { Setting of } \\
\text { practice }\end{array}$} & $\begin{array}{l}\text { Academic } \\
(\mathrm{n}=33)\end{array}$ & 27 (81.8) & $6(18.2)$ & \multirow[t]{2}{*}{$\begin{array}{l}\chi^{2}=0.138 \\
p=0.710\end{array}$} \\
\hline & $\begin{array}{l}\text { Non- } \\
\text { academic } \\
(\mathrm{n}=32)\end{array}$ & $25(78.1)$ & 7 (21.9) & \\
\hline \multirow[t]{2}{*}{$\begin{array}{l}\text { EBM Use } \\
\text { in practice }\end{array}$} & No $(n=6)$ & $6(100.0)$ & $0(0.0)$ & \multirow[t]{2}{*}{$\begin{array}{l}F E=1.562 \\
p=0.335\end{array}$} \\
\hline & $\begin{array}{l}\text { Yes }(\mathrm{n}= \\
59)\end{array}$ & $46(78.0)$ & $13(22.0)$ & \\
\hline \multirow[t]{2}{*}{$\begin{array}{l}\text { EBM } \\
\text { Training }\end{array}$} & No $(n=41)$ & $32(78.0)$ & $9(22.0)$ & \multirow[t]{2}{*}{$\begin{array}{l}\chi 2=0.037 \\
p=0.847^{*}\end{array}$} \\
\hline & $\begin{array}{l}\text { Yes } \\
(\mathrm{n}=24)\end{array}$ & $20(83.3)$ & $4(16.7)$ & \\
\hline
\end{tabular}

*Yate's Correction applied; FE =Fisher's Exact Test

EBM - Evidence-based Medicine

\section{Relationship between perceived barriers to EBM and professional characteristics of the respondents}

In Table 6a, the proportions of respondents who agreed that lack of time was a barrier to EBM were comparable across groups. Significantly higher proportions of Group I respondents and respondents who were trained in EBM disagreed that lack of conclusive evidence was a barrier to $\operatorname{EBM}(\mathrm{p}=0.025$ and $\mathrm{p}=0.004$ respectively). Higher proportions of respondents who worked in nonacademic settings and those who were trained in EBM disagreed about lack of computing resources being a barrier to EBM ( $p=0.045$ and $p=0.023$ respectively). Higher proportions of respondents in Group I, those in non-academic settings and those who were trained on EBM also disagreed that lack of access to electronic 
database was a barrier to EBM use $(\mathrm{p}=0.007, \mathrm{p}=0.002$

and $\mathrm{p}<0.001$ respectively).

\begin{tabular}{|c|c|c|c|c|c|c|}
\hline \multicolumn{3}{|l|}{ Lack of time } & \multirow{2}{*}{$\frac{\text { Agreed }}{12(50.0)}$} & \multirow{2}{*}{$\frac{\text { Undecided }}{0(0.0)}$} & \multirow{3}{*}{$\begin{array}{l}\text { Disagreed } \\
12(50.0) \\
18(43.9)\end{array}$} & \multirow{3}{*}{$\begin{array}{l}\text { Statistics } \\
\mathrm{FE}=3.819 ; \\
\mathrm{P}=0.155\end{array}$} \\
\hline & Duration & Group $\mathrm{I}(\mathrm{n}=24$ & & & & \\
\hline & & Group II $(n=41)$ & $17(41.5)$ & $6(14.6)$ & & \\
\hline & Setting & Academic $(n=33)$ & $15(45.5)$ & $2(6.0)$ & $16(48.5)$ & $\chi^{2}=0.664$ \\
\hline & & Non-Academic $(n=32)$ & $14(43.8)$ & $4(12.5)$ & $14(43.8)$ & $P=0.766$ \\
\hline & EBM Trained & No $(n=41)$ & $19(46.3)$ & $3(7.4)$ & $19(46.3)$ & $\chi^{2}=0.561$ \\
\hline & & Yes $(n=24)$ & $10(41.7)$ & $3(12.5)$ & $11(45.8)$ & $P=0.804$ \\
\hline \multicolumn{7}{|c|}{ Lack of conclusive evidence } \\
\hline & Duration & Group I $(n=24$ & $10(41.7)$ & $0(0.0)$ & $14(58.3)$ & $\mathrm{FE}=7.041$ \\
\hline & & Group II $(n=41)$ & $19(46.3)$ & $8(19.6)$ & $14(34.1)$ & $\mathrm{P}=0.025$ \\
\hline & Setting & Academic $(n=33)$ & $14(42.4)$ & $6(18.2)$ & $13(39.4)$ & $\chi^{2}=2.162$ \\
\hline & & Non-Academic $(n=32)$ & $15(46.9)$ & $2(6.2)$ & $15(46.9)$ & $\mathrm{P}=0.376$ \\
\hline & EBM Trained & No $(n=41)$ & $21(51.2)$ & $8(0.0)$ & $12(29.3)$ & $\mathrm{FE}=10.675$ \\
\hline & & Yes $(n=24)$ & $8(33.3)$ & $0(0.0)$ & $16(66.7)$ & $P=0.004$ \\
\hline \multicolumn{7}{|c|}{ Lack of computing resources } \\
\hline & Duration & Group I $(n=24$ & $12(50.0)$ & $0(0.0)$ & $12(50.0)$ & $\mathrm{FE}=5.190$ \\
\hline & & Group II $(n=41)$ & $25(61.0)$ & $5(1.2)$ & $11(26.8)$ & $P=0.06$ \\
\hline & Setting & Academic $(n=33)$ & $19(57.6)$ & $5(15.2)$ & $9(27.2)$ & $\mathrm{FE}=5.958$ \\
\hline & & Non-Academic $(n=32)$ & $18(56.2)$ & $0(0.0)$ & $14(43.8)$ & $P=0.045$ \\
\hline & EBM Trained & No $(n=41)$ & $26(63.4)$ & $5(12.2)$ & $10(24.4)$ & $\mathrm{FE}=7.071$ \\
\hline & & Yes $(n=24)$ & $11(45.8)$ & $0(0.0)$ & $13(54.2)$ & $\mathrm{P}=0.023$ \\
\hline \multicolumn{7}{|c|}{ Lack of access to electronic database } \\
\hline & Duration & Group I $(n=24$ & $12(50.0)$ & $0(0.0)$ & $12(50.0)$ & $\mathrm{FE}=9.612$ \\
\hline & & Group II $(n=41)$ & $25(61.0)$ & $8(19.5)$ & $8(19.5)$ & $\mathrm{P}=0.007$ \\
\hline & Setting & Academic $(n=33)$ & $19(57.6)$ & $8(24.2)$ & $6(18.2)$ & $\mathrm{FE}=11.725$ \\
\hline & & Non-Academic $(n=32)$ & $18(56.3)$ & $0(0.0)$ & $14(43.7)$ & $P=0.002$ \\
\hline & EBM Trained & No $(n=41)$ & $28(68.3)$ & $8(19.5)$ & $5(12.2)$ & $\mathrm{FE}=19.198$ \\
\hline & & Yes $(n=24)$ & $9(37.5)$ & $0(0.0)$ & $15(62.5)$ & $\mathrm{P}<0.001$ \\
\hline
\end{tabular}

*FE = Fisher's Exact Test; EBM - Evidence-based Medicine

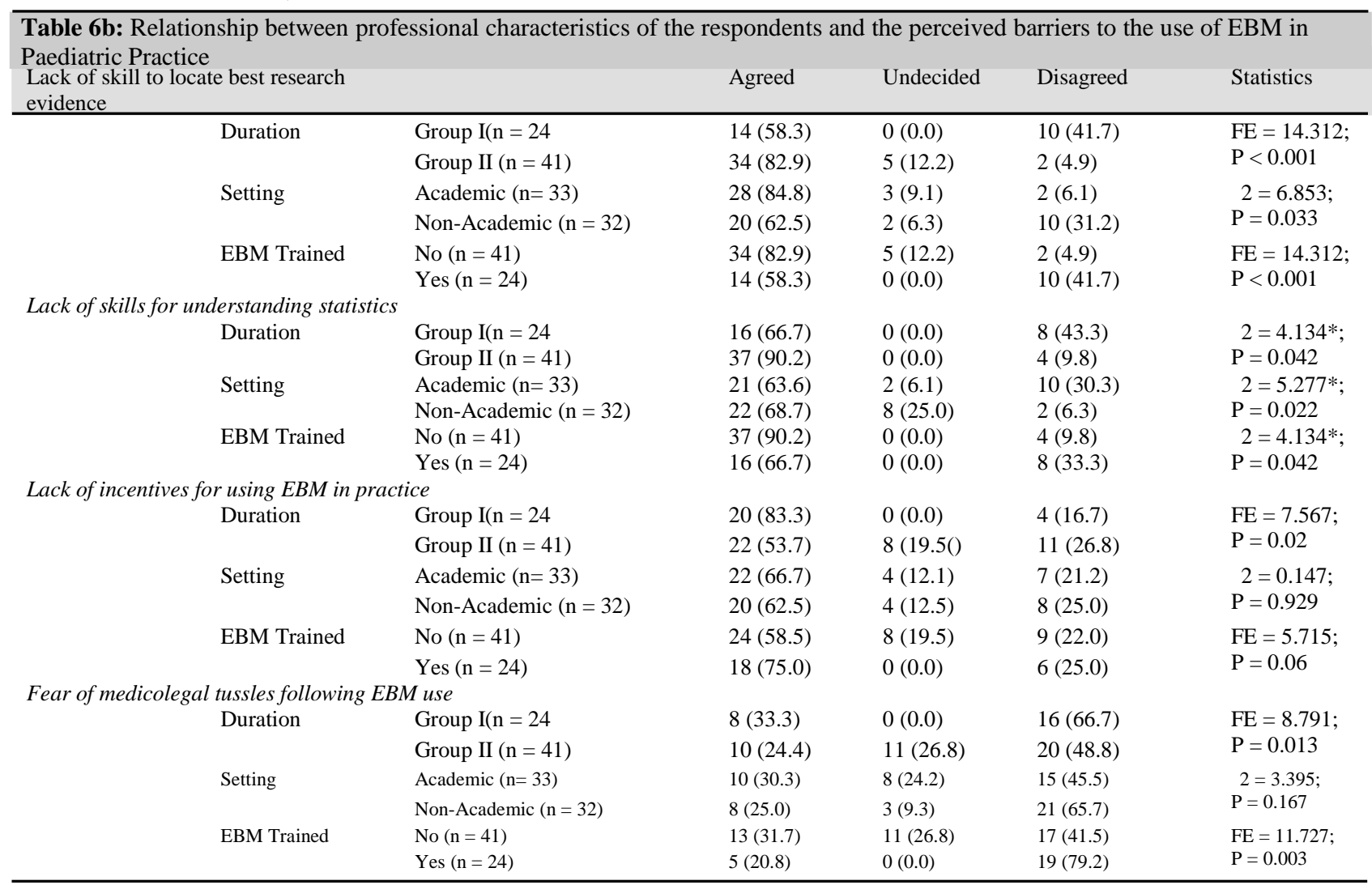

*Chi-Square with Yate's Correction; FE = Fisher's Exact Test; EBM - Evidence-based Medicine 
Table $6 \mathrm{~b}$ shows that higher proportions of Group I respondents, respondents in non-academic settings and respondents trained in EBM disagreed that lack of skills required to locate best research evidence is a barrier to EBM use $(\mathrm{p}<0.001, \mathrm{p}=0.033$ and $\mathrm{p}<0.001$ respectively). Lack of skills for understanding statistics was not perceived as a barrier to EBM by significantly higher proportions of Group I respondents, respondents in the academic setting and respondents who were trained on EBM ( $p=0.042, p=0.022$ and $p=0.042$ respectively). In addition, a significantly higher proportion of Group I respondents agreed that lack of incentives for using EBM in practice was a barrier to the use of EBM ( $p=0.02)$. Significantly higher proportions of respondents in Group I and those who were trained in EBM disagreed that there may be medicolegal tussles following $\operatorname{EBM}$ use $(p=0.013$ and $p=0.003$ respectively).

\section{Discussion}

The present study revealed that almost all the respondents $(90.8 \%)$ used EBM in their clinical practices suggesting a high level of acceptability of EBM in the population. This contrasts with $40 \%$ EBM use rate reported among doctors in Jordan $^{9}$ and $5 \%$ each reported in Sudan and Jordan. ${ }^{7,10}$ The observed difference may be explained in terms of differences in the degree of exposure to EBM during professional workshops and conferences over time. However, the high use rate of EBM in the present study contrasted sharply with the low proportion of participants $(36.9 \%)$ who had received training on EBM. This pattern was similar to the findings among a cohort of Nigerian specialist trainees, where 96.6\% were familiar with EBM but only $38.8 \%$ had been formally trained on EBM. ${ }^{11}$ This low rate of training was similar to $15 \%$ and $24 \%$ previously reported in Sudan and Sri Lanka respectively. ${ }^{10,12}$ This observation may be related to the poor awareness of training opportunities as currently provided by organisations such as the various national and regional Cochrane Centres. It is plausible that paucity of funds and logistic supports may actually limit the number of people that such orgnisations could admit for training at a time. Interestingly, the higher cadre participants in the present study were four times more likely to have received training on EBM compared to the junior cadre participants. The reason for this observation is obscure but it is plausible that the senior participants had better access to training opportunities by virtue of hierarchy in the profession. The universal recommendation of the participants in the present study that training on EBM should be incorporated into postgraduate training curricula may provide a solution to the lopsidedness in the pattern of EBM training in relation to the duration of practice.

Fourth-fifth of the participants in the present study had high knowledge of what EBM entails and what purpose it serves. This is not surprising as the overall mean knowledge score was $77.6 \%$ compared to $24 \%$ recorded in a population of Iranian doctors. ${ }^{13}$ Although the relatively high knowledge score observed in the present study is reassuring, it may not be a perfect proof of deep knowledge of EBM, given the low rate of training reported in the same population. Almost all the participants $(92.3 \%)$ were willing to learn the skills required to incorporate EBM into their routine clinical practice and this may be a reflection of the acceptability of EBM in clinical practice.

The major perceived barriers to the use of EBM in the present study included the lack of skills for understanding statistics, lack of skills for locating best research evidence and lack of incentives for using EBM. Interestingly, the fear of medicolegal tussles arising from the practice of EBM was the least identified barrier. The lack of time was not perceived a leading barrier in the present study unlike other previous studies in Jordan, ${ }^{9}$ Sudan, ${ }^{10}$ Saudi Arabia, ${ }^{14}$ Norway, ${ }^{15}$ and Sri Lanka. ${ }^{12}$ This may reflect the heterogeneous nature of the participants in the various cited studies. Lower cadre doctors are likely to be busier in terms of clinical duties than the higher cadre doctors, who are mostly involved in administrative duties alongside academics with some involvement in clinical duties. Therefore, studies focused on higher cadre doctors, like the present study, are not likely to report lack of time or overwhelming workload as perceived barriers to the practice of EBM. However, the challenge of lack of time, though coming a distant sixth position on a list of eight in the present study, may be addressed by incorporating research day-off on a weekly or bi-weekly basis into the duty schedule for doctors at all levels.

Lack of understanding of statistics and lack of skills for searching and locating best research evidence are training issues which frequent Continuing Medical Programmes can address to a large extent. Access to internet EBM databases such as the Cochrane Library and the World Health Organisation Reproductive Health Library, may need to be improved, just as an earlier study in Bosnia Herzegovina ${ }^{16}$ reported that $34.6 \%$ of doctors did not know how to use the Cochrane database similar to $38.5 \%$ observed in the present study. Institutions should be encouraged to subscribe to these databases and facilitate easy and hitch-free access and use by doctors, particularly when they are not kept busy with clinical duties. Lack of evidence as a perceived barrier to the use of EBM had been reported by Al-Almaie in Saudi Arabia. ${ }^{17}$ That may be related to the fact that the Cochrane Database of Systematic Reviews display many systemic reviews with inconclusive findings arising from either small number of study participants or poor design of the primary randomized controlled trials. Therefore, this dearth of studies with conclusive findings should not deter doctors from the use of the available facts. In addition, this should also stimulate more research in the form of well-designed, high quality randomized controlled trials to answer some of the yet unanswered research questions. 
$\mathrm{Al}-\mathrm{Omari}{ }^{7}$ reported threat to clinical freedom as a perceived barrier to the use of EBM among doctors in Jordan but that fear of medicolegal tussle surrounding the use of EBM did not appear strong in the present study. This difference may be related to the relative rate of medical litigations in each environment. Where treatment protocols have been drawn for routine clinical practice from the best quality evidences available, it becomes difficult to defend any other clinical decision aside the recommendations of the treatment protocol and that may predispose to litigations. In Nigeria, the process of generating treatment protocols for paediatric practice are still on-going, hence there is no pressure for mandatory adherence to specific practices yet. Therefore, medicolegal issues may not yet be perceived as a threat to the use of EBM.

The Group I participants (relatively higher in the hierarchy) and those who had received trainings on EBM were more likely to disagree with the perceptions of lack of computing skills, lack of access to electronic databases, lack of skill to locate the best research evidence, lack of skill for understanding statistics, lack of incentives and fear of medicolegal tussles as barriers to EBM. This observation may be explained in terms of the role of experience on perceptions. The perceived barriers are usually routinely addressed during EBM training and with practice, every researcher learns that the perceived barriers can be adequately overcome.

\section{Conclusion}

In conclusion, the knowledge of this population of Nigerian paediatricians about EBM was good but most of the participants crave better understanding of the statistical aspects of systematic reviews and EBM. The participants also recommended the inclusion of EBM training in both the undergraduate and postgraduate medical curricula as well as in Continuing Medical Education programmes. With adequate training, the perceived barriers to use of EBM will be addressed and appropriate solutions will be provided.

The electronic method of gathering the responses of the participants is acknowledged as a limitation to the study as it may explain the low response rate.

Conflict of interest: None

Funding: None

\section{References}

1. Oladapo OT. Research synthesis: Implications for clinical practice in Nigeria. International J Multi disciplinary Research 2012; V(1\&2): 4-6.

2. Rosenberg WM, Sackett DL. On the need for evidence based medicine. Therapie 1996; 51 (3): 212-217.

3. Collins JA. Clinical research evidence and clinical practice. Hum Reprod 1997; 12(9): 1847 -1850 .

4. Mahmoud AO, Ayanniyi AA, Lawal A, Omolase CO, Ologunsua Y, Samaila E. Survey of medical specialists on their attitudes to and resources for health research in Nigeria. Ann Afr Med 2011; 10(2): 144149.

5. Mahmoud AO, Ayanniyi AA, Lawal A, Omolase CO, Ologunsua Y, Samaila E. Perceptions of Nigerian medical specialists on research. J Public Health Afr 2011; 2(1): el. Doi: 10.4081/jphia.2011.e1

6. Sackett DL, Rosenberg WM. Th need for evidence-based medicine. J R Soc Med 1995; 88(11): 620-624.
7. Higgins J, Green S. Cochrane Handbook for Systematic Reviews of Interventions. Cochrane Book Series. WilleyBlackwell. Chichester, West Sussex, England. 2008.

8. Barghouti F, Halaseh L, Said T, Mousa AH, Dabdoub A. Evidence-based medicine among Jordanian family physicians: awareness, attitude and knowledge. Can Fam Physician 2009; 55(7): e6-e13.

9. Zeidan AZ, Behairy MM. Knowledge, attitude and practice of Evidence-based medicine among residence doctors in Sudan. Sudan J Med Sci 2010; 5(3): 2007-2012.

10. Al Omari M, Khader Y, Jadallah K, Dauod AS, Al-Shdifat AA, Khasawneh NM. Evidence -based medicine among hospital doctors in Jordan: awareness, attitude and practice. $J$ Eval Clin Pract 2009; 15(6): 1137-1141.

11. Fawole A, Oladapo O, Enahoro F, Akande E. Acceptance of evidence-based reproductive health care among postgraduate specialist trainees in Nigeria. Int $J$ GynaecolObstet 2008; 102(1): 3-7.
12. Abeysena $\mathrm{C}$, Jayawardana $\mathrm{P}$, Wickremasinghe R, Wickramansinghe U. Evidence-based medicine knowledge, attitudes and practices among doctors in Sri Lanka. J Evid Based Med 2010; 3(2): 83-87.

13. Rashidbeygi M, Sayehmiri K. knowledge and attitude of physicianstowarss evidence based medicine in Ilam, Iran. Iran Red Crescent J 2013; 15 (9): 798-803.

14. Al-Musa HM. Knowledge, perceptions, attitude and educational needs of physicians to evidence based medicine in South-Western Saudi Arabia. Saudi Med J 2010; 31(3): 308 -312 .

15. Ulvenes LV, Aasland O, Nylenna M, Kristianseh IS. Norwegian physicians' knowledge of and opinions about evidence-based medicine: cross-sectional study. PLoS One 2009; 4(11): e7828. Doi: 10.1371/ journal.pone.0007828. 
16. Mahmić-KaknjoM, Kadić D, Hodžic H, Spahić-Sarajlić S, Hadžic E, Ademović E. Awareness, knowledge, use and attitude towards evidence based medicine in a developing country: Survey of physicians in a canton in Bosnia and Herzegovina. Croat Med J 2015; 56(6): 558-566.
17. Al-Almaie SM, Al-Baghli N. Barriers facing physicians physicians practicing evidence based medicine in Saudi Arabia. J ContinEduc Health Prof 2004; 24(3): 163-170. 